\title{
Comparative Study of Captopril Derivatization Reaction by LC-UV, LC-MS and CE-UV Methods ${ }^{\dagger}$
}

\author{
Gabriella Donáth-Nagy, ${ }^{\mathrm{a}}$ Szende Vancea, ${ }^{\mathrm{a}, *}$ and Silvia Imre ${ }^{\mathrm{b}}$ \\ ${ }^{a}$ University of Medicine and Pharmacy of Târgu-Mureş, Faculty of Pharmacy, Department of Physical Chemistry, \\ 38 Gh. Marinescu Street, RO-540139 Târgu-Mures, Romania \\ ${ }^{\mathrm{b}}$ University of Medicine and Pharmacy of Târgu-Mureş, Faculty of Pharmacy, Department of Drugs Analysis, \\ 38 Gh. Marinescu Street, RO-540139 Târgu-Mures, Romania \\ RECEIVED OCTOBER 18, 2010; REVISED JULY 30, 2011; ACCEPTED SEPTEMBER 1, 2011
}

\begin{abstract}
The LC-UV, LC-MS and CE-UV study of chemical reaction between captopril and $p$-bromophenacyl bromide as derivatizing reagent is reported. During transformation of captopril, its thiol group is involved and the reaction is irreversible. Neutral or alkaline environments favor derivatization. The yield of reaction increases linear with the concentration of the reagent, while changes in temperature do not influence it significantly. Kinetic studies show that derivatization of captopril flows quickly, reaching a plateau after 30 minutes. Based on the study of these effects some important parameters such as deri- vatizing agent concentration, reaction time, temperature and $\mathrm{pH}$ were confined. The results were used for development of captopril determination methods both in pharmaceutical formulations and biological samples. (doi: 10.5562/cca1787)
\end{abstract}

Keywords: captopril, derivatization, LC-UV, LC-MS, CE-UV

\section{INTRODUCTION}

Captopril (CAP) is an angiotensin converting enzyme inhibitor, used as antihypertensive agent. It is common that ACE inhibitors have low UV absorbtivity values and besides that captopril is very instable, undergoes to oxidation, the degradation product being the dimer. ${ }^{1}$ Moreover, captopril also binds to endogenous compounds (cysteine, glutathione). The mentioned properties make the determination of these drugs very difficult. $^{2-4}$ To improve detection and to stabilize the compound a derivatizing agent can be used. In our case the UV active agent was $p$-bromophenacyl bromide ( $p$-BPB), which prevents captopril binding to plasma constituents and is also a chemical stabilizer. ${ }^{5-8}$ The resulted product can be determined at a more specific wavelength $(\lambda=260 \mathrm{~nm})$. The possible reaction between the derivatizing agent and captopril involves the -SH group of the latter and the carbocation of the alkylhalide, ${ }^{9}$ resulting a derivative with greater molecular mass and less polarity (Figure 1).

The aim of our study was to optimize several parameters of the derivatization reaction to get a good yield of transformation, to use these parameters in sample processing and to apply the derivatization in deter- mination methods of captopril from biological matrices or pharmaceutical preparations.

\section{EXPERIMENTAL}

\section{Materials and Methods}

All the reagents were of analytical or reagent grade purity. The derivatization reaction was followed by CEUV, LC-UV and LC-MS methods.

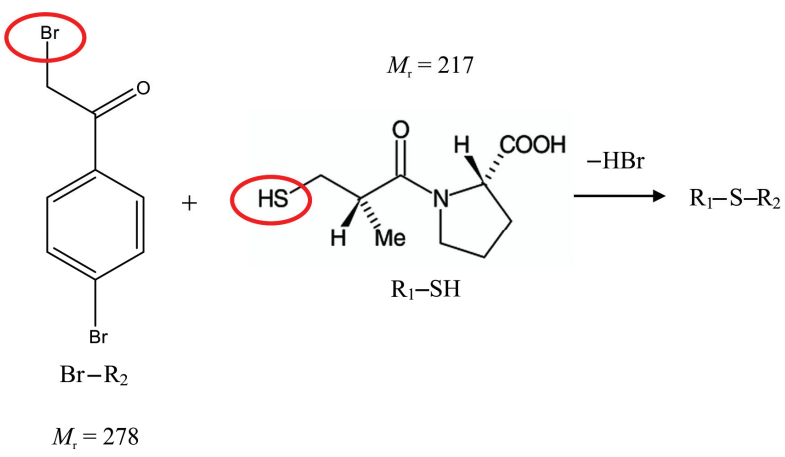

Figure 1. The coupling reaction between $\mathrm{CAP}$ and $p$-BPB, resulting a $M_{\mathrm{r}}=414$ product.

\footnotetext{
$\uparrow$ Presented at the $10^{\text {th }}$ International Symposium and Summer School on Bioanalysis within the CEEPUS Network CII-HU-001004-0910, Zagreb, Croatia, July 2010.

* Author to whom correspondence should be addressed. (E-mail: szende_17@yahoo.com)
} 
For preliminary studies a low cost CE-UV method was developed: The instrument was an Agilent $6100 \mathrm{CE}$ System, with an uncoated capillary $(l=38 \mathrm{~cm}, 50 \mu \mathrm{m}$ i.d.). The temperature was set at 23 and $40{ }^{\circ} \mathrm{C}$, buffer solution used $\mathrm{KH}_{2} \mathrm{PO}_{4}\left(c=20 \mathrm{mmol} \mathrm{dm}{ }^{-3}\right)+\mathrm{NaOH}(c=$ $\left.0.1 \mathrm{~mol} \mathrm{dm}^{-3}\right), \mathrm{pH}=7.7$. Polarity: positive, voltage: 20 $\mathrm{kV}$, Injection: pressure of 5 mbar applied during $5 \mathrm{~s}$. UV detection was performed at 205 and $260 \mathrm{~nm}$.

For HPLC-UV studies the following assembly was used. The instrument was an Agilent 1100 series, chromatographic column was a Zorbax SB-C8 Solvent Saver Plus, $l=3 \times 100 \mathrm{~mm}, 3.5 \mu \mathrm{m}$ i.d., the column temperature was set at $35^{\circ} \mathrm{C}$. Mobile phase: phosphoric acid $(c=15$ mmol $\left.\mathrm{dm}^{-3}\right)$ in water-acetonitrile $(w=60-40 \%)$, flow: $1 \mathrm{~mL} \mathrm{~min}^{-1}$, with gradient elution as described in Table 1.

The injection volume was $10 \mu \mathrm{L}$, the detector was set at 205 and $260 \mathrm{~nm}$.

For the LC-MS method, the liquid chromatograph was an Agilent 1200 series, equipped with a Chromolith Performance $100 \times 4.6 \mathrm{~mm}, 3 \mu \mathrm{m}$ i.d. column (Merck). The column temperature was set at $30{ }^{\circ} \mathrm{C}$. The mobile phase consisted in a mixture between $\mathrm{A}$ : formic acid $0.1 \%$ in water; $\mathrm{B}$ : acetonitrile in isocratic elution $\mathrm{A}: \mathrm{B}=$ $60: 40 \%$, flow $1 \mathrm{~mL} \mathrm{~min}^{-1}$. The injection volume was $20 \mu \mathrm{L}$. The mass spectrometer, IonTrap SL 1100 series (Agilent), used an ionization source ESI+. The detection was in MRM mode, the monitored ions were 216, 253, $255,368,370 \mathrm{~m} / \mathrm{z}$ fragmented from $415 \mathrm{~m} / \mathrm{z}$ parent ion of the derivative.

Extraction of captopril from tablets: 20 tablets, each containing $25 \mathrm{mg}$ captopril, were weighed and the average mass of one tablet was determined. A quantity of powder, corresponding to a content of $10 \mathrm{mg}$ captopril, was extracted with approximatelly $7 \mathrm{ml}$ water in a $10 \mathrm{~mL}$ volumetric flask in the ultrasonic bath (for 10 minutes), then brought to volume with water and filtered through the filter with the pore size of $0.45 \mu \mathrm{m}$. The resulted solution $\left(\gamma=1 \mathrm{mg} \mathrm{mL}^{-1}\right)$ was diluted 20 fold with water to reach the desired captopril concentration of $50 \mu \mathrm{g} \mathrm{mL}^{-1}(0.5 \mathrm{~mL}$ of initial captopril solution was dilluted with water in $10 \mathrm{~mL}$ volumetric flask). The derivatization reaction was performed as follows: 200 $\mu \mathrm{L}$ from this sample was mixed with $20 \mu \mathrm{L} 0.1 \mathrm{M} \mathrm{KOH}$ and $40 \mu \mathrm{L}$ RD. After 15 minutes the mixture was neutralized with $30 \mu \mathrm{L}$ of $1 \mathrm{M} \mathrm{HCl}$, then injected to HPLC.

Sample preparation from plasma samples: Standard and test plasma samples were prepared as follows in order to be chromatographically analyzed. In an Eppendorf tube $0.2 \mathrm{~mL}$ plasma with $40 \mu \mathrm{L}$ RD solution was vortex-mixed for 30 seconds. After 30 minutes, while the derivatization reaction was completed, the tube was shaken again for 30 seconds with $0.3 \mathrm{~mL}$ methanol, and then centrifuged for 10 minutes at 14000 rpm. The supernatant was transferred in an autosampler vial and $20 \mu \mathrm{L}$ were injected into the LC-MS system.
Table 1. Gradient elution during HPLC-UV run

\begin{tabular}{cc}
\hline$t / \min$ & $w$ (acetonitrile $) / \%$ \\
\hline 0 & 40 \\
5 & 40 \\
5.1 & 95 \\
8 & 95 \\
8.1 & 40 \\
11 & 40 \\
\hline
\end{tabular}

Table 2. Calibration curves in analytical runs (peak area $=$ $a \times c+b ; n=4$ series)

\begin{tabular}{ccrc}
\hline Series & $10^{-4} a$ & $10^{-4} b$ & $\begin{array}{c}\text { Determination } \\
\text { coefficient } R^{2}\end{array}$ \\
\hline $\mathrm{CC}_{1}$ & 2.40 & -3.75 & 0.9990 \\
$\mathrm{CC}_{2}$ & 2.13 & 1.04 & 0.9987 \\
$\mathrm{CC}_{3}$ & 2.32 & -2.34 & 0.9985 \\
$\mathrm{CC}_{4}$ & 2.18 & 3.10 & 0.9935 \\
$\mathrm{Mean}$ & 2.26 & -1.96 & 0.9974 \\
$\mathrm{SD}$ & 0.12 & 3.12 & 0.0026 \\
\hline
\end{tabular}

Table 3. Accuracy (relative error of the found concentration) reported to the nominal and precision (variation coefficient) results, expressed in \%

\begin{tabular}{lllll}
\hline & QCA & QCB & QCC & QCD \\
\hline$c_{\text {nom. }} / \mu \mathrm{g} \mathrm{mL}^{-1}$ & 24.0 & 28.0 & 50.00 & 80 \\
$c_{\text {rec. } 1} / \mu \mathrm{g} \mathrm{mL}^{-1}$ & 23.3 & 28.6 & 50.97 & 83 \\
$c_{\text {rec. } 2} / \mu \mathrm{g} \mathrm{mL}^{-1}$ & 23.8 & 28.7 & 50.91 & 84 \\
$c_{\text {rec. } 3} / \mu \mathrm{g} \mathrm{mL}^{-1}$ & 23.5 & 27.9 & 50.91 & 80 \\
$\mathrm{Mean} / \mu \mathrm{g} \mathrm{mL}^{-1}$ & 23.5 & 28.4 & 50.93 & 82.3 \\
$\mathrm{SD}$ & 0.3 & 0.4 & 0.03 & 2.1 \\
$\mathrm{CV} / \%$ & 1.1 & 1.5 & 0.07 & 2.5 \\
$\mathrm{Er} / \%$ & 2.3 & 1.4 & 1.90 & 2.9 \\
\hline
\end{tabular}

\section{RESULTS AND DISCUSSION}

The electrophoretic method was used only for preliminary studies, to observe whether the reaction occurs or not. Firstly the electropherograms of the two reactants (CAP and $p$-BPB) were recorded, then those of their mixture, at 30 minutes after mixing. This electropherogram shows three peaks: the $p$-BPB being neutral migrates together with EOF, captopril, being the most negatively charged, is the last that migrates. The third peak that appeared is the derivative's one, which migrates in front of captopril, being less negatively charged and more voluminous (Figure 2). 
The presence of three peaks on the electropherogram shows that the reaction occurs and the product (derivative) is formed.

For further studies we switched to an HPLC-UV instrument, which gives better reproducibility for quantitative data and better determination of lower concentrations. With this method the parameters of derivatization reaction were optimized.

The Captopril: Derivatizing Agent Ratio

The optimum molar ratio was found to be CAP : $p$-BPB $=1: 1.4$.

\section{The $\mathrm{pH}$ of the Reaction Medium}

The reaction is favored by alkaline medium but it also occurs with acceptable rate at neutral $\mathrm{pH}$, which is important for plasma sample analysis (Figures 3 and 4).

\section{Reacting Time}

The time necessary for a complete transformation is about 30 minutes at neutral $\mathrm{pH}$, in alkaline medium the reaction occurs instantaneously (3-5 minutes).

\section{Reaction Kinetics}

The kinetic profile of the derivatization reaction was recorded using 5 parallel determinations at the following sampling times: $0.5,1.0,2.0,4.0,6.0,8.0,10.0$, 15.0, 20.0, and 30.0 minutes.

The reaction order can be determined by the graphical method, plotting the peak area $y / \mathrm{mAU}$ min (which is proportional to the concentration of analyte) $v s$. time. The best fit to our data was achieved using a three parameter logarithmic function (Figure 5):

$$
y=a-b \times \ln (x+c)
$$

The obtained kinetic function was:

$$
\begin{gathered}
\text { peak area }=639+539 \times \ln (t+0.3) \\
\text { peak area } \propto c
\end{gathered}
$$

Considering peak area $\mathrm{a}_{\max } / 2=2500 / 2=1250 \mathrm{mAU}$ min, using the obtained equation, the half-life time can be calculated, being $t_{1 / 2}=2.8 \mathrm{~min}$. This value is in good agreement with the experimental data (in approximately 3 minutes the half of the initial quantity of captopril is derivatized).

The reaction rate can be expressed as the integrated form of the above equation, in our case:

$$
v=\frac{\mathrm{d} y}{\mathrm{~d} x}, \quad v=\frac{b}{x+c}
$$

So the equation of the reaction rate is:

$$
v=\frac{k}{t+0.3}
$$

and the rate constant: $k=b=539 \mathrm{AU}$.

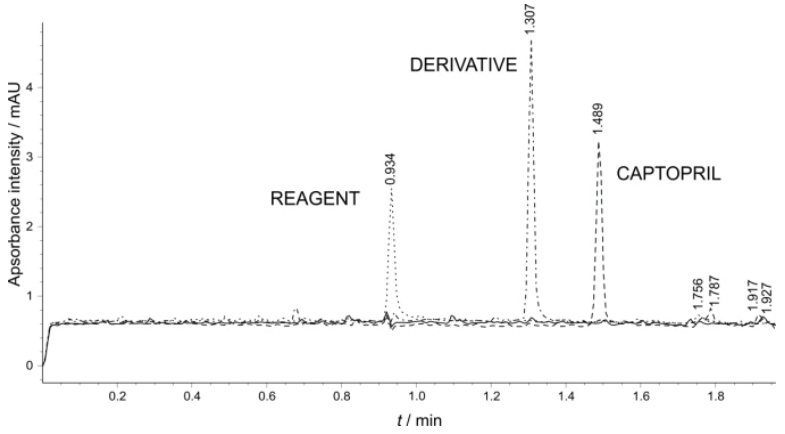

Figure 2. The overlaid electropherograms of a blank sample $(-)$, captopril (--), $p$-BPB $(\cdots)$, and their mixture at 30 minutes after mixing $(-\cdots)$ detected at $\lambda=205 \mathrm{~nm}$.

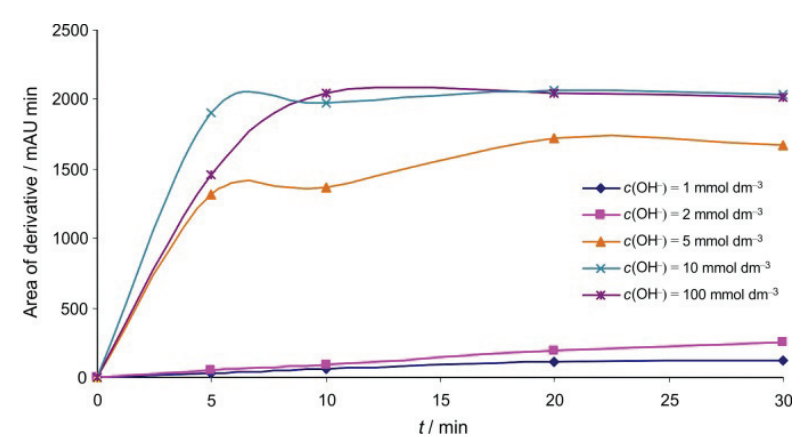

Figure 3. Kinetic profile of the reaction at alkaline $\mathrm{pH}=9-10$ (achieved with $\mathrm{NaOH}$ or $\mathrm{KOH}, c=1-100 \mathrm{mmol} \mathrm{dm}^{-3}$ ).

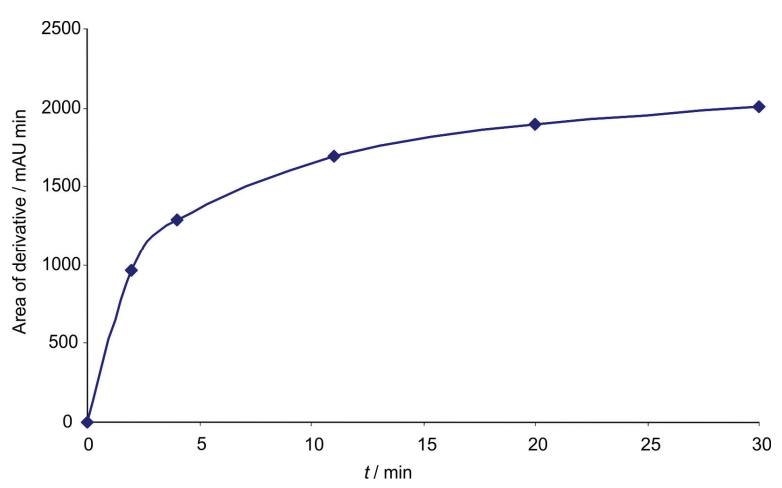

Figure 4. Kinetic profile of the reaction at neutral $\mathrm{pH}=7.4$ (achieved with ammonium formate or $\mathrm{KH}_{2} \mathrm{PO}_{4}+\mathrm{NaOH}$ buffer).

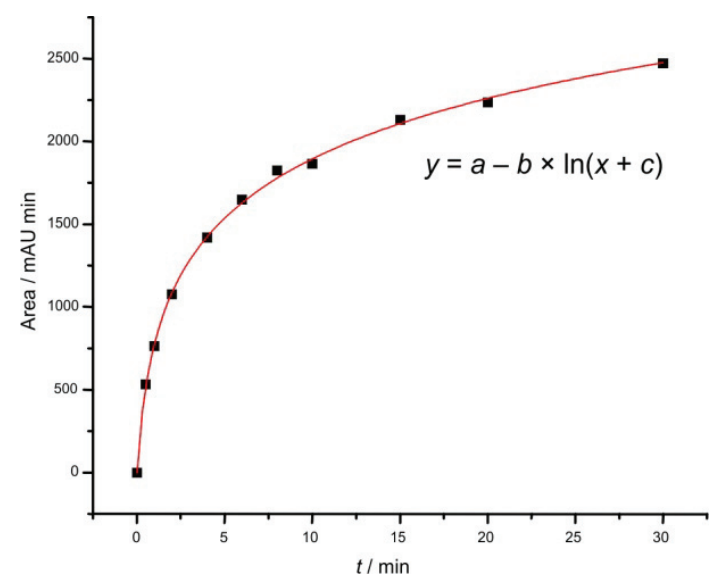

Figure 5. Fitting function for reaction's kinetic profile. 

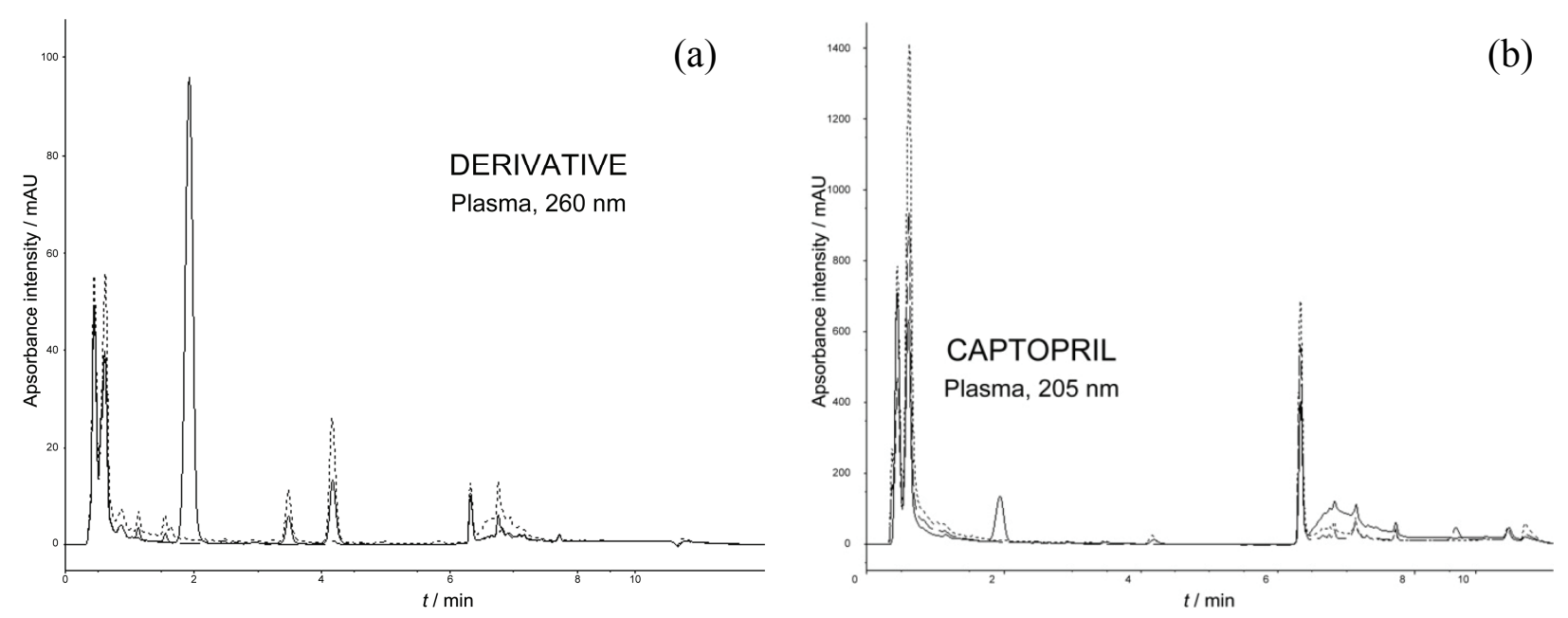

Figure 6. The chromatogram of the derivative (a) at $\lambda=260 \mathrm{~nm}$ and captopril (b) at $\lambda=205 \mathrm{~nm}$.
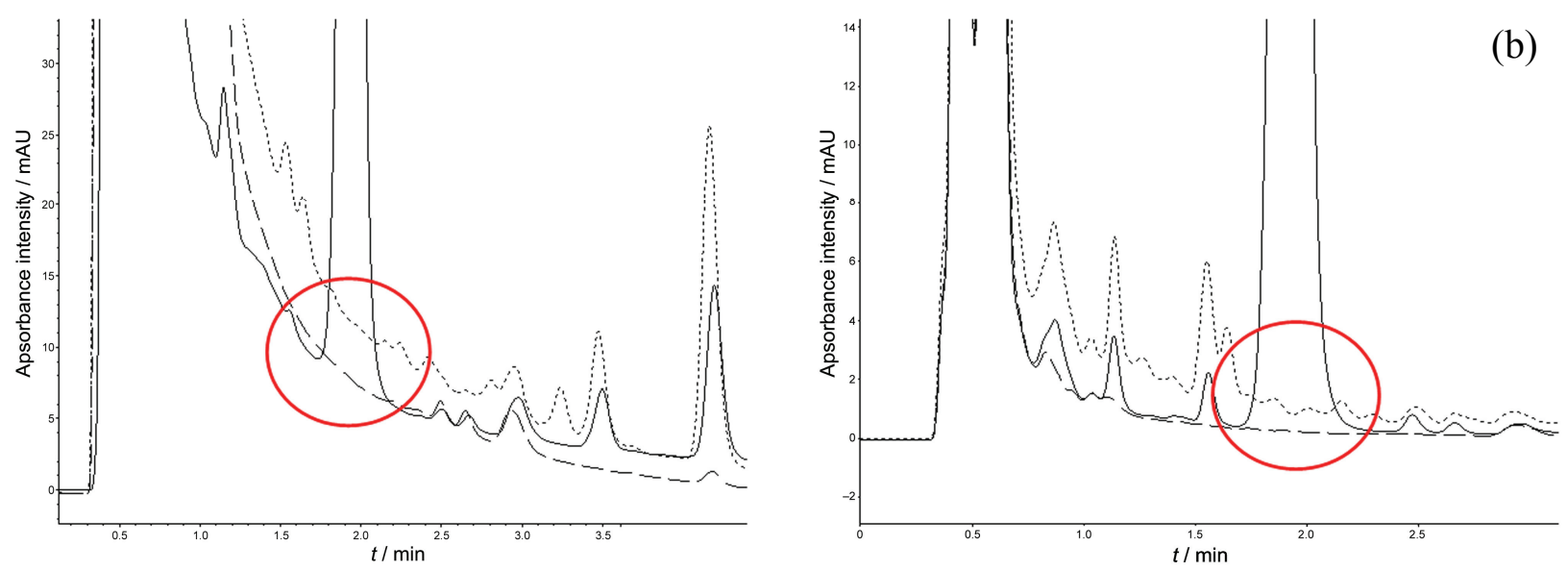

Figure 7. The $\mathrm{S} / \mathrm{N}$ ratio in case of captopril (a) at $\lambda=205 \mathrm{~nm}$, and derivative (b) at $\lambda=260 \mathrm{~nm}$.

By HPLC-UV method a good separation of the derivative was achieved even in the presence of plasma matrix constituents. The detection of the derivative at $260 \mathrm{~nm}$ is much more selective than of captopril at 205 nm (Figure 6).

The detection limits calculated were minimum 1.0 $\mu \mathrm{g} \mathrm{mL}^{-1}$ for underivatized Captopril at $205 \mathrm{~nm}$, and 0.1 $\mu \mathrm{g} \mathrm{mL}^{-1}$ in case of derivative, at $260 \mathrm{~nm}$. So the specificity of wavelength allows 10 times lower detection limit for captopril as derivative (Figure 7).

The developed HPLC-UV method is suitable for determination of captopril from pharmaceutical formulations, e.g. tablets. Linearity of the method was verified in the $12-100 \mu \mathrm{g} \mathrm{mL}^{-1}$ concentration range, with six calibration standards, the results are presented in Table 2 .

The method has good accuracy and precision in the linearity range, Er and CV found to be below $3 \%$ (Table 3).

The captopril content from tablets $\left(C_{\mathrm{CAT}}\right.$, expressed in mg per tablet) is calculated using the sample concentration determined from the calibration curve $\left(\gamma_{\mathrm{cc}}\right.$, expressed in $\left.\mu \mathrm{g} \mathrm{mL}^{-1}\right)$, the average mass $\left(m_{\text {mean }} / \mathrm{g}\right)$ of the
20 tablets, the amount of sample taken $\left(m_{\text {sample }} / \mathrm{g}\right)$, and taking into account also the dilution that was made:

$$
C_{\mathrm{CAT}}=\gamma_{\mathrm{cc}} \cdot \frac{m_{\text {mean }}}{m_{\text {sample }}} \cdot \frac{1}{5}
$$

where $\gamma_{\mathrm{cc}}=48.84 \mu \mathrm{g} \mathrm{mL}{ }^{-1} ; m_{\text {mean }}=0.14 \mathrm{~g} ; m_{\text {sample }}=$ $0.056 \mathrm{~g}$ (Figure 8).

Substituting known values into the formula, the result is $C_{\mathrm{CAT}}=24.42 \mathrm{mg}$, which corresponds to official regulations, assay of content in tablets $\pm 7.5 \%$, which means that captopril content has to be in the range of $23.125-26.875 \mathrm{mg}$.

Taking in consideration the detection limits from HPLC-UV method, we can conclude that this method is still not suitable for bioequivalence and pharmacokinetic studies, where the plasma concentration of captopril is only of $\mathrm{ng} \mathrm{mL} \mathrm{mL}^{-1}$ (pg mL $\mathrm{m}^{-1}$ injected to column) magnitude. This low-concentration problem can be solved by two ways:

(i) Purification and concentration of samples by solid phase extraction (SPE) or liquid- liquid extraction (LL), but both are time consuming and very laborous. 


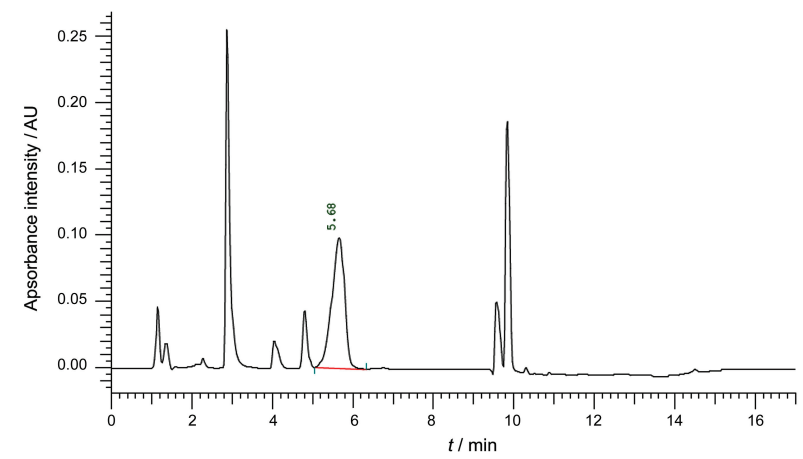

Figure 8. Chromatogram of captopril solution extracted from tablets (final concentration $50 \mu \mathrm{g} / \mathrm{mL}$ )

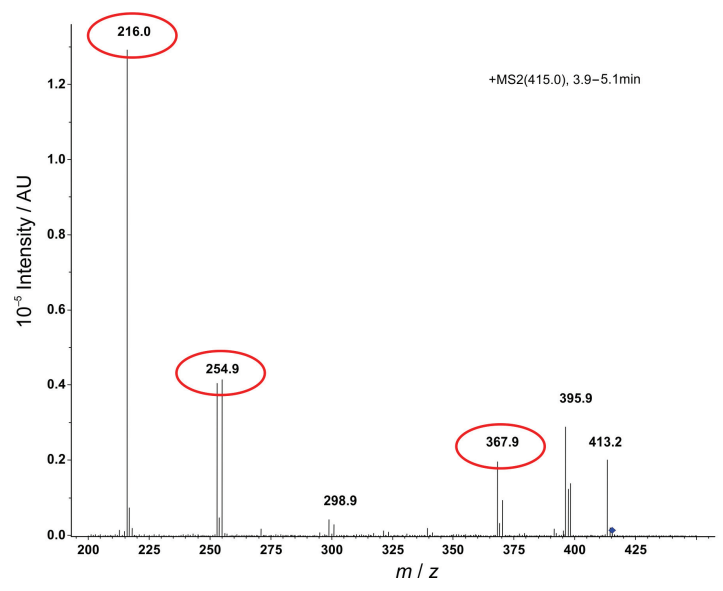

Figure 9. The MS/MS spectrum of the derivative. The monitored ions were $216,253,255,368,370 \mathrm{~m} / \mathrm{z}$ fragmented from $415 \mathrm{~m} / \mathrm{z}$ parent ion of the derivative.

(ii) Use of more sensitive, specific and efficient detection mode, like MS or MS/MS.

The second way was considered being more efficient, so for further experiments an LC-MS method was used.

The MS/MS spectrum of the derivative is presented in Figure 9. The monitored ions were the MRM $216,253,255,368$ and $370 \mathrm{~m} / z$, fragmented from the parent ion $415 \mathrm{~m} / \mathrm{z}$.

This HPLC-MS/MS method was able to quantify free captopril in human plasma after oral administration of a single dose of $100 \mathrm{mg}$ captopril by applying a simple protein precipitation. Despite the sensitivity of the
LC-MS/MS method, prior derivatization is needed in order to prevent captopril disulphide formation during sample processing and storage. The developed and validated method was used for bioequivalence investigation of two oral medicinal products containing captopril on a large number of human plasma samples. The results of the study were published previously by us. ${ }^{10}$

\section{CONCLUSIONS}

An LC-UV, LC-MS and CE-UV study of chemical reaction between captopril and $p$-bromophenacyl bromide as derivatizing reagent was reported. During transformation of captopril, its thiol group is involved and the reaction is irreversible. The reaction occurs at room temperature in alkaline and neutral media as well, reaching a plateau after 30 minutes at neutral $\mathrm{pH}$. The reaction follows a complex kinetic; the calculated half-life time $(2.8 \mathrm{mi}-$ nutes) corresponds to the experimentally observed value. The optimized method of captopril determination was successfully applied to pharmaceutical formulations (HPLC-UV-25 mg tablets), and biological samples (bioequivalence study, HPLC-MS human plasma).

\section{REFERENCES}

1. C. M. Pereira and Y. K. Tam, Am. J. Health Syst. Pharm. 49 (1992) 612-615

2. N. C. C. Borges, M. A. G. Heleno, and R. A. Moreno, Rev. Bras. Med. 63 (2006) 518-522.

3. K. R. Rezende, I. M. Mundim, L. S. Teixeira, W. C. Souza, D. R. Ramos, C. R. F. Cardoso, I. C. Souza, M. Z. Gratao, and K. B. Bellorio, J. Chromatogr. B. 850 (2007) 59-67.

4. I. Salem, W. A. Saif, and Y. Jmeian, J. Pharm. Biomed. Anal. 37 (2005) 1073-1080.

5. M. Bahmaei, A. Khosravi, C. Zamiri, A. Massoumi, and M. Mahmoudian, J. Pharm. Biomed. Anal. 15 (1997) 1181-1186.

6. T. Huang, Z. He, B. Yang, L. Shao, X. Zheng, and G. Duan, J. Pharm. Biomed. Anal. 41 (2006) 644-648.

7. A. Jankowski, A. Skorek, K. Krzyko, P. K. Zarzycki, R. J. Ochocka, and H. Lamparczyk, J. Pharm. Biomed. Anal. 13 (1995) 655-660.

8. S. Gao, W. Tian, and S. Wang, J. Chromatogr. 582 (1992) 258-262.

9. T. Toyo'oka, Modern Derivatization Methods for Separation Sciences, John Wiley \& Sons Ltd, Chichester, England, 1999, pp. $78-98$.

10. Sz. Vancea, S. Imre, G. Donáth-Nagy, B. Tőkés, M. Nyulas, T. Muntean, and R. Borka-Balás, Talanta 79 (2009) 436-441. 